\title{
Modal Sensitivity Analysis and Structural Optimization of the Cab of Light Truck
}

\author{
Qi Xiaomin \\ School of Mechanical and Automotive \\ Engineering \\ Anhui Polytechnic University \\ Wuhu, Anhui Province, China \\ qxm0909@163.com
}

\author{
Ding Fang \\ Department of Automotive Engineering \\ Anhui Technical College of \\ Mechanical and Electrical Engineering \\ Wuhu, Anhui Province, China
}

\author{
Xu Dezhang \\ Anhui Key Laboratory of Anvanced \\ Numerical Control \& Servo \\ Technology \\ Wuhu, Anhui Province, China
}

\begin{abstract}
White body finite element model of a light-truck cab is established, with which numerical and experimental modal calculations and analysis are conducted. Based on modal matching principle, a dynamic characteristics analysis is performed, and on the same time, the cab structure optimization is carried out based on the modal first frequency sensitivity analysis. By the structure optimization, the first torsion frequency of the cab is reduced, and the difference between the first torsion frequency and the excitation frequency with the engine idling is increased. To some extent the purpose of reducing vibration and noise is achieved.
\end{abstract}

Keywords- cab; modal; sensitivity; finite element; optimization

\section{INTRODUCTION}

In the process of moving, due to the excitation of various vibration sources, there is vibration in the cab of car. When the external excitation frequency and the natural frequency of the cab is approaching, resonance will be generated. In order to improve the reliability of the truck and riding comfort, the inherent mode analysis must be carried out, whether the structure of cab is reasonable, it is necessary to evaluate the structure of cab from the point of view of the modal parameters[1]. The cab vibrations come from mode superposition of each mode, where in, the first few steps of the overall mode is the main factor. Because the first order modal frequency of the cab is close to the engine idling excitation frequency, so, an important indicator of the evaluation of the dynamic performance of the cab is the first order overall torsional frequency.

In this paper, through modal sensitivity analysis, the first order modal frequency of the cab of light truck is optimized, we make it avoid engine idling excitation frequency, so as to reduce the vibration and noise, improve the driving comfort and reliability.

\section{MODAL ANALYSIS OF THE CAB}

\section{A. Establishing Finite Element Model of The Shell Element}

Fig.1 is finite element model of the cab, all parts of the entire cab are thin stampings, simulated by shell element. There are 68230 quadrilateral elements and 7125 triangular elements

The work reported in this paper is supported by National Natural Science Foundation of China (No.51175001), and by the Natural Science Foundation of Anhui Province, China (No.11040606M144). The authors also would like to thank the financial supports of the Research Foundation of Education Bureau of Anhui Province, China (No. KJ2011B016, KJ2012B011). in the model.

\section{B. Numerical Modal Analysis}

Do not impose any constraints and force, carrying on preprocessing of the finite element model of the cab and the free numerical modal analysis. Due to the vibration of the cab by the low-level frequency, when in the calculation of $1 \sim 100 \mathrm{~Hz}$ frequency range, the top six order modal frequencies and vibration modes are extracted. The natural frequencies and the corresponding modes (enlarged 20 times) are shown in Fig. 2.
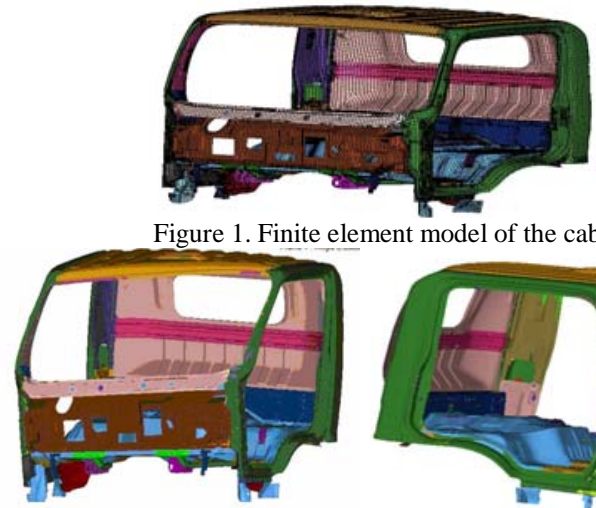

(a) $22.17 \mathrm{~Hz}$ The first vibration mode
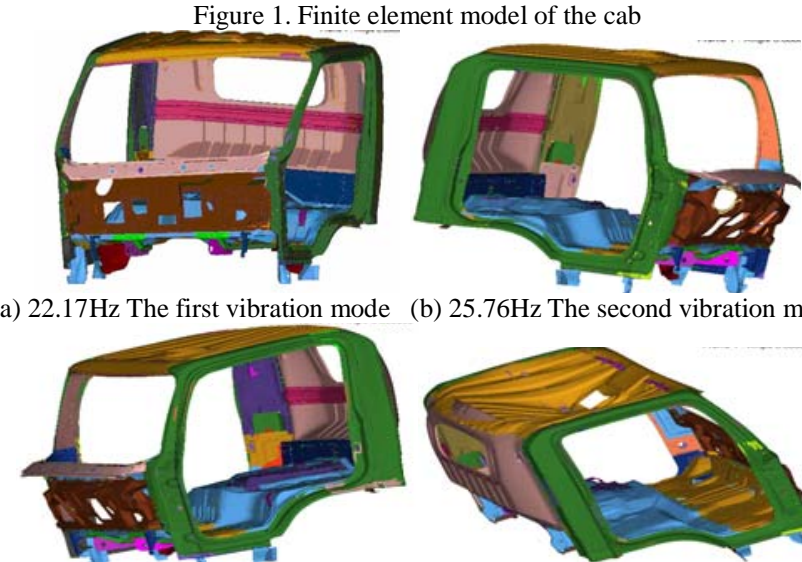

(b) $25.76 \mathrm{~Hz}$ The second vibration mode

(c) $30.15 \mathrm{~Hz}$ The third vibration mode
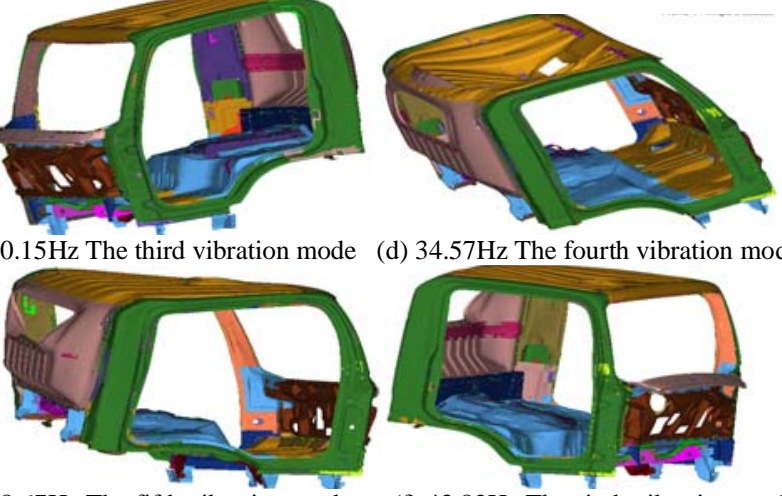

(d) $34.57 \mathrm{~Hz}$ The fourth vibration mode

(e) $38.67 \mathrm{~Hz}$ The fifth vibration mode

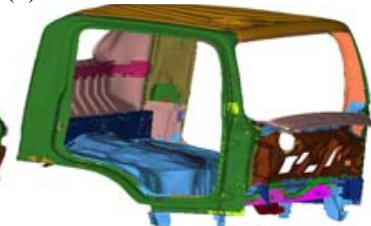

(f) $43.82 \mathrm{~Hz}$ The sixth vibration mode

Figure 2. natural frequencies of numerical modal analysis and corresponding mode shapes 


\section{Experimental Modal Analysis}

In addition to numerical modal analysis, experimental modal analysis is also carried out this paper. In this test, there are 130 points, taking the single vibration point for vibration, vibration signal using sine sweep signal, sweeping the range of $0 \sim 200 \mathrm{~Hz}$, sweep frequency speed is $0.2 \mathrm{~Hz} / \mathrm{s}$, a sweep time about half an hour or so. We take the top six order of 1 to $100 \mathrm{~Hz}$ frequency range of modal frequencies and vibration modes. Each vibration mode is shown in Figure 3. Numerical modal frequency and experimental modal frequency value comparison as is shown in Table I .

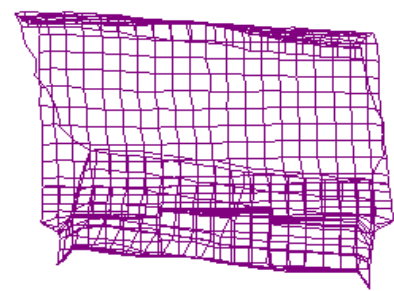

(a)The first vibration mode of experimental modal

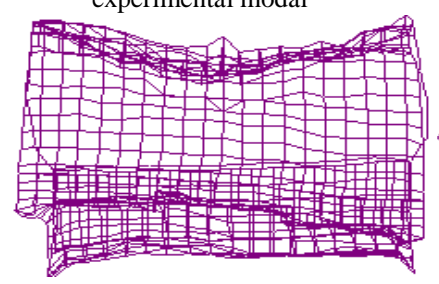

(c)The third vibration mode of experimental modal

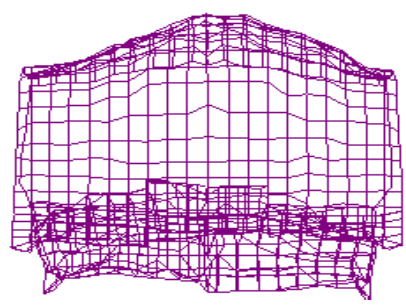

(e)The first vibration mode of experimental modal

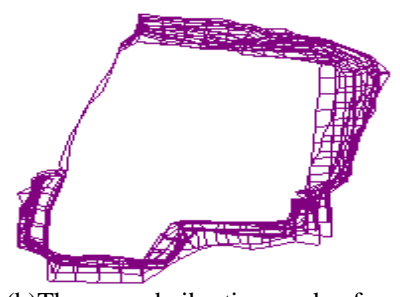

(b)The second vibration mode of experimental modal

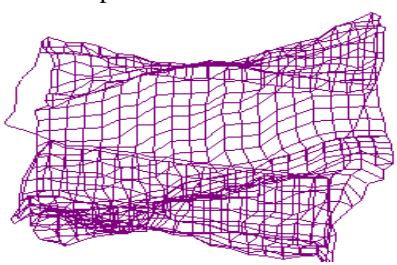

(d)The fourth vibration mode of experimental modal

Figure 3. The natural frequencies of experimental modal analysis and corresponding mode shapes

TABLE I NATURAL FREQUENCY BETWEEN THE NUMERICAL MODAL RESULTS AND THE EXPERIMENTAL MODAL RESULTS

\begin{tabular}{|c|c|c|c|}
\hline $\begin{array}{c}\text { Modal order } \\
\text { number }\end{array}$ & $\begin{array}{c}\text { Modal frequency } \\
\text { of computation/Hz }\end{array}$ & $\begin{array}{c}\text { Modal frequency } \\
\text { of experiment/Hz }\end{array}$ & $\begin{array}{c}\text { Relative } \\
\text { error } \\
(\%)\end{array}$ \\
\hline 1 & 22.17 & 21.75 & $-1.89 \%$ \\
\hline 2 & 28.76 & 29.51 & $2.61 \%$ \\
\hline 3 & 30.15 & 31.39 & $4.11 \%$ \\
\hline 4 & 34.57 & 33.86 & $-2.05 \%$ \\
\hline 5 & 38.67 & 36.78 & $-4.89 \%$ \\
\hline 6 & 43.82 & 44.33 & $1.16 \%$ \\
\hline
\end{tabular}

As can be seen from Table I, there is certain error between the numerical modal results and the experimental modal results, the main reasons are we omit some local structure characteristics, as well as errors caused by support error, sensor additional quality error and external interference. But the relative error is less than $10 \%$, it is shown that the finite element model of the cab is accurate, and the overall dynamics of the cab is very good[3].

\section{StRUCTURAL OptimizATION BASED ON MODAL SENSITIVITY ANALYSIS}

Under idle speed conditions, the frequency of the light truck's engine can be calculated by the formula $\mathrm{H}=(\mathrm{N} / 60) \times \mathrm{M}$, where $\mathrm{N}$ is an idling engine speed, $\mathrm{M}$ is a half of the number of strokes. This light truck is four-stroke engine, and speed is about $700 \mathrm{r} / \mathrm{min}$ under idle speed conditions, so $\mathrm{N}$ takes 700r/min, $\mathrm{M}$ takes 2.Calculated by the above formula, the excitation frequency of the light truck's engine is $23.3 \mathrm{~Hz}$, this value is very close to the first order overall torsional frequency $22.17 \mathrm{~Hz}$, so it is easy to cause resonance, thus the riding comfort and the life of the structure are affected[4]. We must optimize the structure of the, and reduce the vibration and noise.

\section{A. Modal Sensitivity Analysis}

The cab of light truck is mainly composed of plate and shell structures. We select the thickness of the main parts as the design variables, the variation in the thickness of the plate is less than $20 \%$ as the dimension constraints, the second order modal frequency value is unchanged small and cab total mass amount of change is less than $5 \%$ as the state constraints. First order modal frequency is selected as the objective function, modal sensitivity analysis is carried out by the OPTISTRUCT solver[5].

Through the analysis of the sensitivity, we get the more sensitive components of the cab, the calculation results is shown in Table II .

TABLE II THE THICKNESS SENSITIVITY VALUE AFFECTED BY THE FIRST MODAL FREQUENCY

\begin{tabular}{|c|c|c|c|}
\hline $\begin{array}{c}\text { Variable } \\
\text { number }\end{array}$ & $\begin{array}{c}\text { Sensitivity } \\
\text { coefficient }\end{array}$ & $\begin{array}{c}\text { Variable } \\
\text { number }\end{array}$ & $\begin{array}{c}\text { Sensitivity } \\
\text { coefficient }\end{array}$ \\
\hline D27 & -0.07 & D49 & 3.76 \\
\hline D2 & -0.08 & D43 & 2.83 \\
\hline D17 & -0.11 & D21 & 0.85 \\
\hline D12 & -0.18 & D30 & 0.79 \\
\hline D56 & -0.20 & D50 & 0.68 \\
\hline D19 & -0.19 & D8 & 0.63 \\
\hline D37 & -0.45 & D5 & 0.60 \\
\hline D30 & -1.57 & D25 & 0.09 \\
\hline
\end{tabular}

As can be seen from Table II, the more sensitive components is D49, D43 and D30, they correspond respectively to the left side wall outer panel, the right side wall outer panel and the roof outer panel, the thickness of the three components is more sensitive by the first order modal frequency. Therefore, we must select the three sensitive 
components for optimization object when performing structural optimization[6].

\section{B. Structural Optimization}

According to the left side wall outer panel, the right side wall outer panel, the roof outer panel and so on, we create the design variables, and according to the constraints variables and objective function, the structure of the cab is optimized by the use of OPTISTRUCT solver. Based on sensitivity analysis results and iteration calculation results, each structure optimized thickness is obtained, and then combined with the actual situation in the production process, and thus to redetermine the thickness of each structural of the cab[7]. The optimization results of cab structure are shown in Table III.

\section{TABLE III THE OPTIMIZATION RESULTS OF CAB STRUCTURE}

\begin{tabular}{|c|c|c|c|}
\hline $\begin{array}{c}\text { Variable } \\
\text { number }\end{array}$ & $\begin{array}{c}\text { Initial value } \\
(\mathbf{m m})\end{array}$ & $\begin{array}{c}\text { Optimized } \\
\text { value } \\
(\mathbf{m m})\end{array}$ & $\begin{array}{c}\text { determined } \\
\text { value } \\
(\mathbf{m m})\end{array}$ \\
\hline D27 & 1.60 & 1.76 & 1.80 \\
\hline D2 & 0.80 & 0.95 & 1.00 \\
\hline D17 & 1.20 & 1.47 & 1.50 \\
\hline D12 & 0.80 & 0.96 & 1.00 \\
\hline D56 & 0.60 & 0.81 & 0.80 \\
\hline D19 & 0.80 & 0.97 & 1.00 \\
\hline D37 & 0.80 & 0.96 & 1.00 \\
\hline D30 & 0.80 & 0.96 & 1.00 \\
\hline D49 & 1.00 & 0.84 & 0.80 \\
\hline D43 & 0.80 & 0.64 & 0.60 \\
\hline D21 & 1.20 & 0.97 & 1.00 \\
\hline D30 & 1.50 & 1.23 & 1.20 \\
\hline D50 & 1.50 & 1.18 & 1.20 \\
\hline D8 & 1.20 & 0.98 & 1.00 \\
\hline D5 & 1.00 & 0.82 & 0.80 \\
\hline D25 & 1.20 & 1.03 & 1.00 \\
\hline
\end{tabular}

After the finally optimization of the cab, the modal analysis is carried out again, the results compare with before optimization results, comparative results are shown in Table IV.
As can be seen from Table IV, through the modal sensitivity analysis of structure optimization, although the total mass of the cab increases slightly, but the total mass of the amount of change is less than $5 \%$, the amplitude is relatively small. After optimization, the first order modal frequency is reduced from $22.17 \mathrm{~Hz}$ to $19.98 \mathrm{~Hz}$, compared to the excitation frequency of the engine idling, it staggers $3.32 \mathrm{~Hz}$. Thus away from the excitation frequency of the engine, the generation of the resonance can be effectively avoided.

\section{CONCLUSION}

In view of the first torsion frequency of the light truck cab is close to the engine idling excitation frequency, the finite element model of the cab is Established, and then modal sensitivity analysis is carried out, the three sensitive components are found, at the same time, the structure of the cab is optimized, making the optimized cab meet other performance conditions, its first order torsion frequency and the engine idling excitation frequency stagger $3.32 \mathrm{~Hz}$. In this case, the resonance is avoided, the purpose of vibration and noise reduction is achieved to some extent, and also the ride comfort and safety are improved.

\section{REFERENCES}

[1] CuiAn,Wang Dengfeng Chen Haichao, "Cab Structural Optimization of a Commercial Vehicle Based on Modal Sensitivity Analysis," Automotive Engineering, vol 32, 2010, pp. 535-539.

[2] Santos F M, Temarel P, Soares C G. "Modal analysis of a fast patrol boat made of composite material,” Ocean Engineering, vol 36, 2009, pp. 179-192.

[3] HO-LE K, "Finite element mesh generation methods," Computer Aided Design,vol 20, 1998, pp.27-38.

[4] Fichera G, LacagninaM. "Modeling of Torsion Beam Rear Suspension by Using Multibody Method," Multibody System Dynamics, vol 12,2005,pp.302 - 316.

[5] Chen Zhi yong, Shi Wenku, Shen Zhihong, "Modal analysis for body and frame of a light-type bus," Journal of vibration and shock,vol 29, 2010, pp. 244-246.

[6] Yang Xiaowei, Liu Yongxuan, Zhou Kongkang. "Effect Analysis of Cab Roof Panel Vibration,” Journal of mechanical engineering, vol 45,2009, pp.221-227

[7] Kodivalam S, Yang R J. "Multidisplinary Design Optimization of a Vehicle System in a Scalable High Performance Computing Environment," Structural and Multidisciplinary Optimization,vol 26, 2004, pp.256-263
TABLE IV RESULTS BEFORE AND AFTER OPTIMIZATION

\begin{tabular}{|c|c|c|c|}
\hline $\begin{array}{c}\text { contrast } \\
\text { parameters }\end{array}$ & $\begin{array}{c}\text { before } \\
\text { optimization }\end{array}$ & $\begin{array}{c}\text { after } \\
\text { optimization }\end{array}$ & $\begin{array}{c}\text { variable } \\
\text { quantity }\end{array}$ \\
\hline total mass $(\mathrm{kg})$ & 170.8 & 172.5 & $0.99 \%$ \\
\hline $\begin{array}{c}\text { first order modal } \\
\text { frequency }(\mathrm{Hz})\end{array}$ & 22.17 & 19.98 & $-9.88 \%$ \\
\hline
\end{tabular}

